\title{
Vertical gradients of lung density in supine subjects with fibrosing alveolitis or pulmonary emphysema
}

\author{
A B Millar, D M Denison
}

\begin{abstract}
Computed tomography was used to determine the vertical gradient of density in the peripheral lung tissue of 12 patients with histologically proved fibrosing alveolitis and 12 patients with chronic bronchitis and evidence of pulmonary emphysema on the computed tomograms. Measurements were made at total lung capacity and at residual volume and compared with similar measurements from 12 normal subjects reported in a previous study. At residual volume the mean peripheral tissue density in the emphysematous lungs was $0.081 \mathrm{~kg} / 1$ compared with $0.426 \mathrm{~kg} / 1$ in the fibrotic lungs and $0.323 \mathrm{~kg} / 1$ in the normal lungs. The observed densities in the three groups were compared with those in a theoretical model predicting the vertical changes of lung density caused by gravitational effects that would be found in lungs with differing compliance. The emphysematous lungs showed a much greater increase of density with descent down the lung than that predicted for normal lungs, and the results were explicable by an increase in compliance. The fibrotic lungs showed considerably less change in density than expected, implying loss of compliance. It is suggested that local changes of compliance are important determinants of vertical density gradients in diseased lungs.
\end{abstract}

We reported previously that measurements of area and density in thoracic computed tomograms taken at total lung capacity (TLC) and residual volume (RV) can be used to assess regional gas and tissue volumes and ventilation in normal and diseased lungs. ${ }^{12}$ We have also investigated the vertical density gradients in the lungs of normal subjects and suggested that they were related to changes in local compliance. ${ }^{3}$ This interpretation was based on the model of the lung in which this behaves as a liquid, open cell foam collapsing under its own weight, as proposed by Wilson and Bachofen in $1982^{4}$ and confirmed recently by Stamenovic and Yager. ${ }^{5}$ Other authors have already commented on the alterations in the vertical density gradients present in thoracic computed tomograms of patients with emphysema $^{6-8}$ or fibrotic lung disease, ${ }^{910}$ as illustrated in figure 1 . We have studied such changes in more detail using information present in the scans and in the lung function results of 12 patients with cryptogenic fibrosing alveolitis and 12 patients who met the Medical Research Council criteria for chronic bronchitis ${ }^{11}$ and who also had evidence of emphysema on their scans. Other aspects of their scans have been reported previously. ${ }^{2}$

\section{Methods}

SUBJECTS AND LUNG MEASUREMENTS

The subjects were selected retrospectively from large groups of patients considered to have probable emphysema or fibrosing alveolitis who had computed tomography performed for clinical reasons. Each patient had detailed lung function tests within 24 hours of their scan. The methods used and normal values have been reported previously. ${ }^{12}$ The 12 patients with fibrosing alveolitis had histologically proved disease. There were eight men and four women, their ages ranging from 21 to 69 years and their height from 161 to $183 \mathrm{~cm}$. Their lung function, expressed as mean (SD) \% predicted, was as follows: forced expiratory volume in one second $\left(\mathrm{FEV}_{1}\right)$ 66(17); forced vital capacity (FVC) 65 (11); residual volume (RV) 58 (13); single breath gas transfer factor (TLCO) 35 (9); transfer coefficient (Kco) 66 (18). The other 12 patients (two women and 10 men; age 43-75 years, height $163-187 \mathrm{~cm}$ ) met the Medical Research Council criteria for chronic bronchitis $^{11}$ and had computed tomography evidence of widespread emphysema. Their lung fuction test results were as follows (mean (SD) \% predicted): FEV 38 (23); FVC 77 (26); TLC 133 (13); RV 220 (63); TLCO 43 (18); KCo 55 (18).

All the computed tomograms were obtained as the patient lay supine. We used an Elscint 2002 whole body scanner, which has a single scan time of five seconds. Data from the scanner were stored on magnetic tape and transferred to a separate viewing console for analysis. The protocol for scanning each subject was identical to that previously described. ${ }^{3}$ The subject was asked to breathe in to TLC and signal when the lungs were full. An inspiratory scan was recorded. This procedure was repeated from lung apex to lung base, with a constant slice width of $1 \mathrm{~cm}$. At the end of inspiratory scans corresponding information was obtained for the lungs at residual volume, the patient being asked to breathe out and signal when the lungs were "empty." The mean densities of successive horizontal planes of peripheral lung tissue were calculated by
Dr of Medicine, Middlesex Hospital, London W1N 8AA. (Reprints will not be available.)

Accepted 21 May 1990 
Figure 1 Computed tomogram of a supine subject with emphysema (a) or fibrosing alveolitis (b) at full inspiration (TLC) in the upper scans and full expiration $(R V)$ in the lower scans, showing the differences in vertical density gradient.
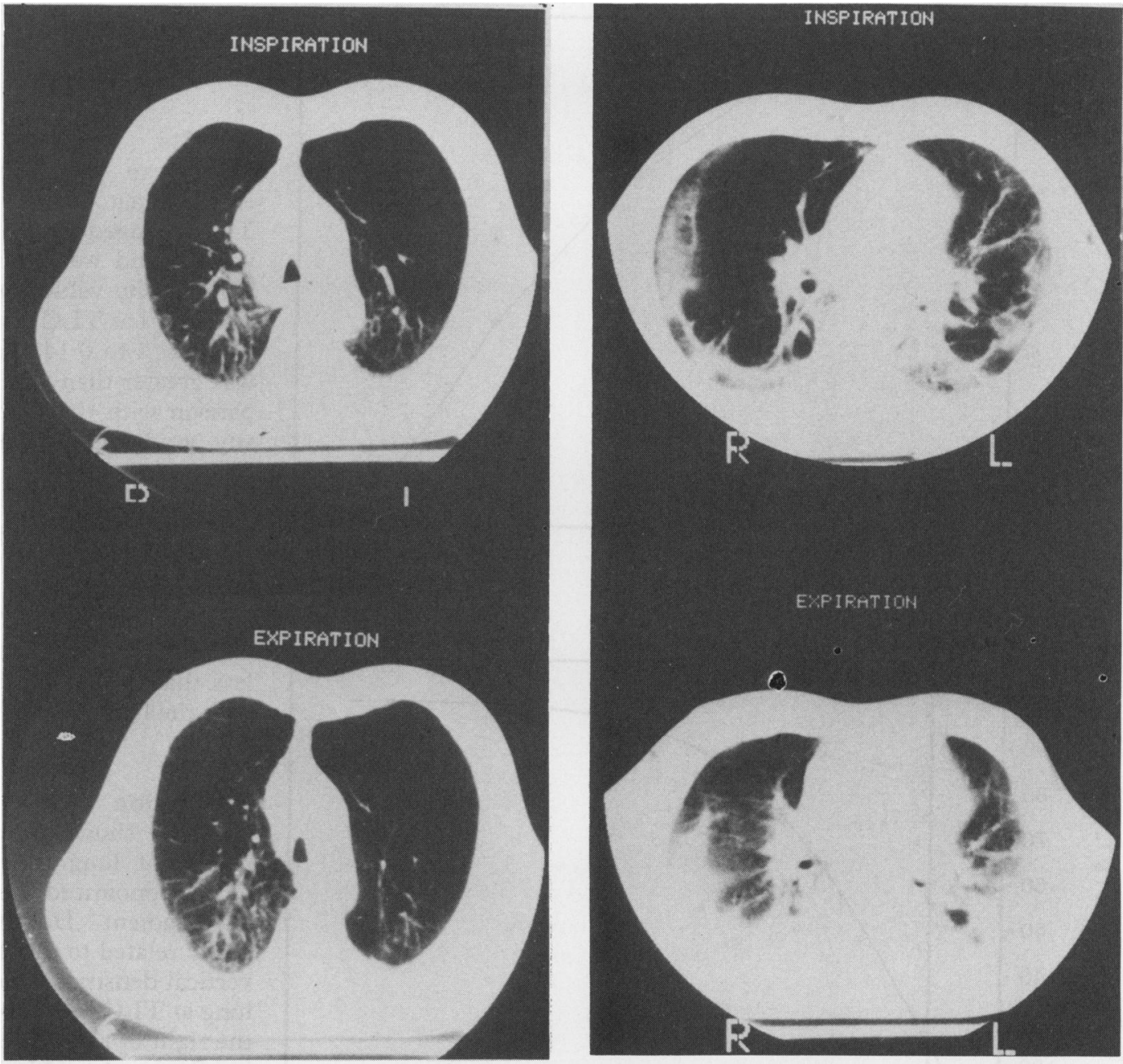

summing values from the equivalent levels in each scan, the mid point of the right atrium being used as the reference level. ${ }^{3}$ The mean (SD) densities of each $1 \mathrm{~cm}$ thick plane of groups of patients are compared in figure 2

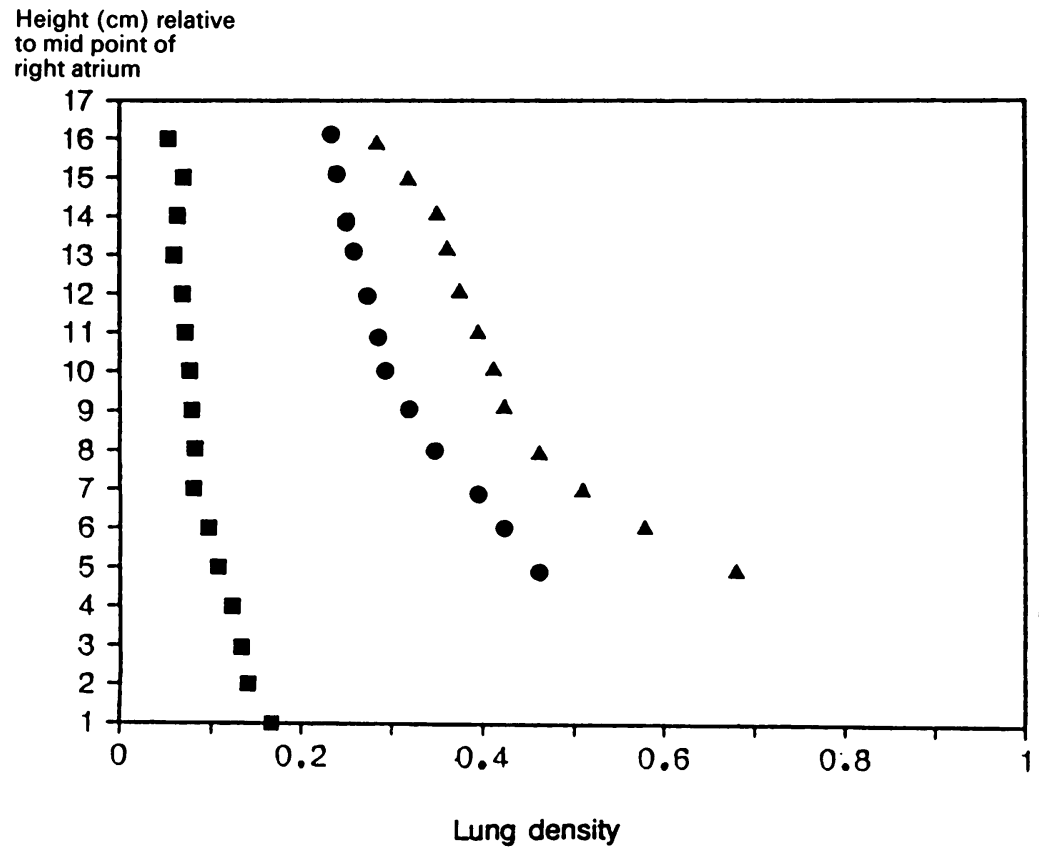

Figure 2 Plot of the mean densities observed at various heights above the bottom of the supine lung by computed tomograms in 12 patients with emphysema (squares), 12 subjects with fibrosing alveolitis (triangles), and 12 normal subjects (circles; from a previous study). All the scans were taken when the lungs were at residual volume. peripheral lung tissue are presented. The densities observed at residual volume in the two with those previously reported for normal subjects. $^{3}$

\section{ANALYSIS}

We described previously a simple mathematical model of a lung like foam to predict the vertical density gradient of normal lung. ${ }^{3}$ In that model the compliance of the lung was assumed to be constant from the top to the bottom of a stack of lung tissue for a given degree of lung inflation. We wished to improve on that model by allowing for variations in lung compliance due to different degrees of inflation within any stack. To do this we began graphically, by differentiating the pressure-volume curve of normal lungfor example, that published by Murray ${ }^{12}$ - to obtain the compliance for each degree of inflation from RV to TLC. Normalised for lung volume, the differential was best fitted by the curve shown in figure $3 a$, for which the equation is:

$\mathrm{CL}=5 \cdot 7-(2 \times \mathrm{VL} / \mathrm{TLC})^{2 \cdot 7}-(\mathrm{VL} / \mathrm{TLC}) \% \mathrm{TLC} / \mathrm{cm} \mathrm{H}_{2} \mathrm{O}$. A synthetic pressure-volume relationship for normal lung obtained by integrating this equation is shown in figure $3 b$. Armed with this equation we calculated the vertical distribution of density in a tall stack of lung tissue collapsing under its own weight. The upper element of the stack was taken to be at 

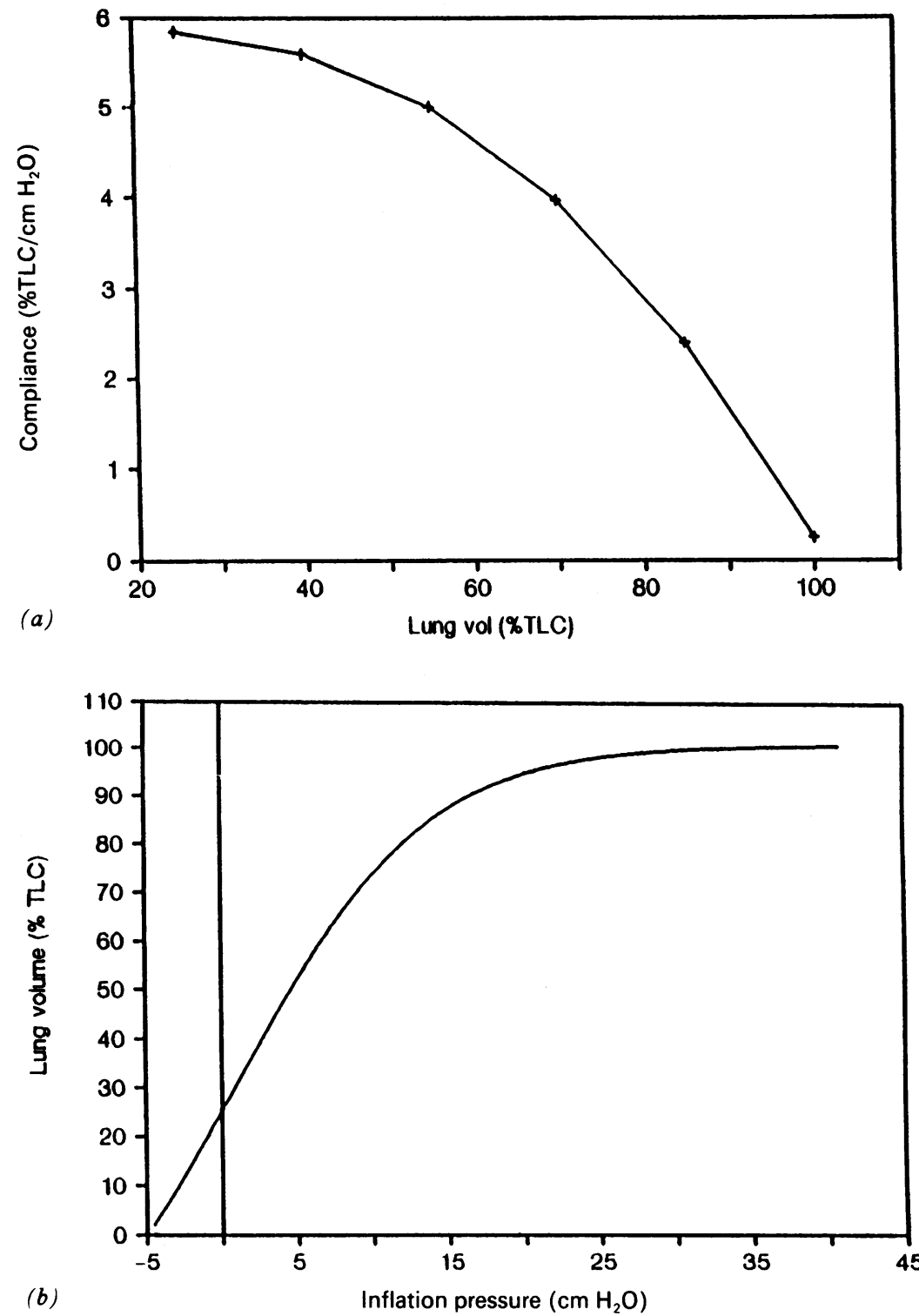

Figure 3 (a) Graphical representation of compliance versus lung volume; (b)pressurevolume curve for normal lung calculated from $(a)$.

$101 \%$ of TLC. We assumed the lung characteristics described by Weibel, with a weight of $825 \mathrm{~g}$ and a TLC of $6400 \mathrm{ml} \cdot{ }^{13}$ At any given degree of whole lung inflation the vertical density gradient within the lung would be represented by some segment of this curve.

Previously we noted that the supine lung is about $17 \mathrm{~cm}$ tall at TLC and shrinks to some $12 \mathrm{~cm}$ at RV. When the stack of lung tissue is related to the mid point of the right atrium, $1 \mathrm{~cm}$ of this reduction in height comes from the top of the stack and $4 \mathrm{~cm}$ from the bottom. ${ }^{3}$ Using that information allows us to take appropriately sized segments from the synthetic curve described above and plot them as the "family" of vertical density gradients to be expected in computed tomograms of normal lungs at various degrees of inflation from TLC to less than normal RV. A selection of such predicted normal vertical density gradients at various degrees of inflation (from greater than TLC on the left to less than RV on the extreme right) is shown by the solid lines in figure 4. We have superimposed the real data of the patients at $R V$ from figure 2 and data from the 12 normal subjects from reference 3.

\section{Results}

The mean peripheral lung density in the emphysematous lungs was $0.061 \mathrm{~kg} / 1$ at TLC. This changed little with reduction in lung volume and was $0.081 \mathrm{~kg} / \mathrm{l}$ at $\mathrm{RV}$ (table 1 ). The density values ranged from $0.039 \mathrm{~kg} / 1$ to $0.103 \mathrm{~kg} / \mathrm{l}$ at TLC in the 12 subjects and from $0.048 \mathrm{~kg} / 1$ to $0 \cdot 142 \mathrm{~kg} / 1$ at $\mathrm{RV}$. The gradient was greater than would be predicted by comparison with the "family" of calculated density gradients shown by the solid lines in figure 4.

In the lungs of patients with fibrosing alveolitis the mean peripheral lung density was $0.211 \mathrm{~kg} / \mathrm{l}$ at TLC and $0.426 \mathrm{~kg} / \mathrm{l}$ at $\mathrm{RV}$. The range of density values in the 12 subjects was from 0.151 to $0.253 \mathrm{~kg} / 1$ at TLC and from 0.295 to $0.620 \mathrm{~kg} / 1$ at $\mathrm{RV}$. The gradient was less than would be predicted by comparison with the family of curves shown in figure 4.

\section{Discussion}

We have shown previously that in normally compliant lung the greater the density the more pronounced the curve-that is, the density gradient. ${ }^{3}$ Density in normal lung is directly related to the degree of inflation; thus a vertical density gradient predicted for normal lung at TLC would be to the left and at RV to the right of the curves for normal lung shown in figure 4. Although the patients with emphysema had lightweight lungs and a low Kco, suggesting reduced pulmonary blood volume, their lungs show a much greater than predicted increase in density towards the bottom of the supine lung, reflecting a substantial increase in compliance. The patients with fibrosis on the other hand, with quite similar losses of pulmonary capillary blood volume, show a less than predicted increase in density with descent down the lung. Their observed gradient is similar to that in the normal subjects with a lower mean density, indicating a considerable loss of compliance.

Comparisons of computed tomograms with lung models and with isolated healthy and diseased lungs show that tomograms provide accurate maps of physical density distributions. ${ }^{14-17}$ Many authors, such as Kreel, observing the vertical density gradients in healthy lungs, have noted that they are more obvious in expiration than inspiration (when most lung units are fully inflated on the plateau of the pressure-volume curve and hence have similar compliance) and that they are inverted with reversal of posture, and have attributed them to the effects of gravity on the pulmonary circulation. Alterations of the vertical density gradients in diseased lungs have also been observed frequently, ${ }^{6-10}$ alterations again being principally attributed to loss, distension, or leakage of vessels. We suggest that vertical density gradients also reflect local lung compliance, especially in expiration.

Global lung compliance was measured in 
Height $(\mathrm{cm})$ relative to mid point of right atrium

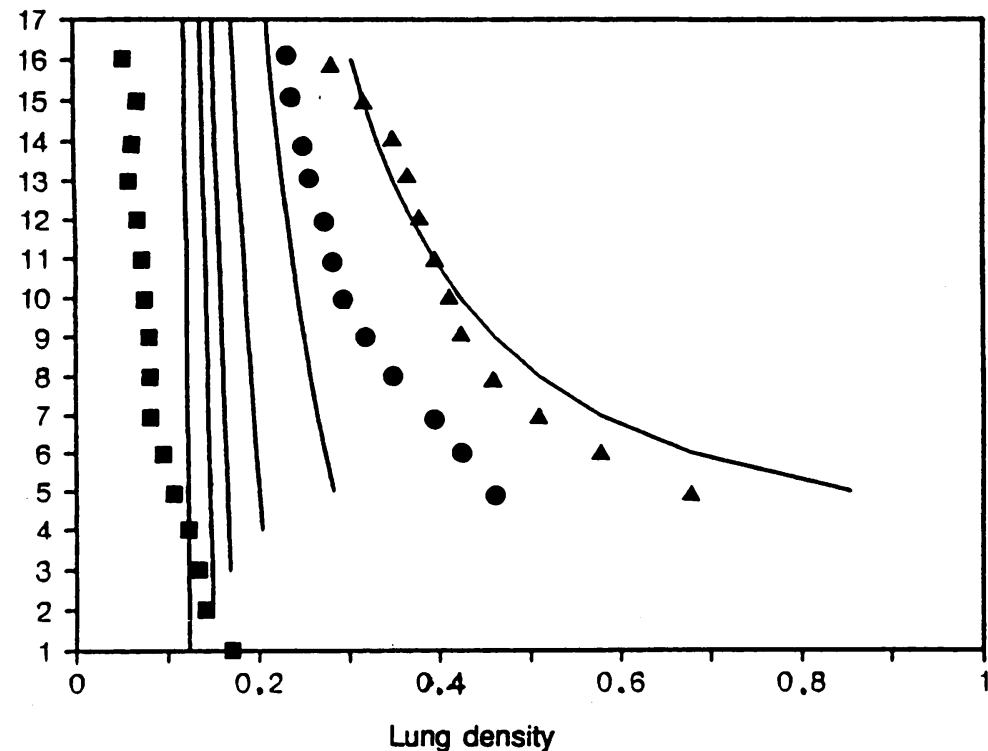

Figure 4 Mean densities observed at residual volume in 12 patients with emphysema (squares), 12 patients with fibrosing alveolitis (triangles), and 12 normal subjects (circles; from a previous study) compared with predicted gradients described in the text (solid lines).

Table 1 Density of cephalocaudal samples of peripheral lung tissue in 12 supine subjects with emphysema

\begin{tabular}{|c|c|c|c|c|}
\hline \multirow{3}{*}{$\begin{array}{l}\text { Height }(\mathrm{cm}) \text { above } \\
(+) \text { or below }(-) \\
\text { mid right atrium }\end{array}$} & \multicolumn{4}{|c|}{ Mean (SD) density $(\mathrm{kg} / \mathrm{l})$} \\
\hline & \multicolumn{2}{|l|}{ Inspiration } & \multicolumn{2}{|l|}{ Expiration } \\
\hline & Right & Left & Right & Left \\
\hline \multirow[t]{2}{*}{$\begin{array}{l}+5 \\
+4 \\
+3 \\
+2 \\
+1 \\
0 \\
-1 \\
-2 \\
-3 \\
-4 \\
-5 \\
-6 \\
-7 \\
-8 \\
-9 \\
-10 \\
-11 \\
-12\end{array}$} & $\begin{array}{l}0.047(0.021) \\
0.049(0.036) \\
0.048(0.029) \\
0.049(0.030) \\
0.050(0.029) \\
0.048(0.025) \\
0.051(0.026) \\
0.047(0.028) \\
0.060(0.045) \\
0.062(0.025) \\
0.060(0.025) \\
0.066(0.035) \\
0.072(0.037) \\
0.077(0.035) \\
0.085(0.037) \\
0.096(0.045) \\
0.099(0.042) \\
0.102(0.049)\end{array}$ & $\begin{array}{l}0.031(0.020) \\
0.035(0.022) \\
0.039(0.024) \\
0.038(0.022) \\
0.040(0.023) \\
0.043(0.021) \\
0.046(0.021) \\
0.043(0.021) \\
0.050(0.021) \\
0.052(0.021) \\
0.057(0.021) \\
0.063(0.022) \\
0.068(0.024) \\
0.069(0.018) \\
0.081(0.029) \\
0.076(0.022) \\
0.078(0.033) \\
0.104(0.051\end{array}$ & $\begin{array}{l}0.052(0.015) \\
0.068(0.043) \\
0.062(0.039) \\
0.059(0.027) \\
0.067(0.036) \\
0.071(0.037) \\
0.074(0.038) \\
0.079(0.037) \\
0.081(0.039) \\
0.081(0.039) \\
0.095(0.049) \\
0.106(0.057) \\
0.120(0.064) \\
0.132(0.069) \\
0.140(0.058) \\
0.170(0.085) \\
\text { Mean }=0.081\end{array}$ & $\begin{array}{l}0.045(0.036) \\
0.050(0.037) \\
0.049(0.034) \\
0.050(0.031) \\
0.055(0.033) \\
0.053(0.030) \\
0.055(0.031) \\
0.058(0.032) \\
0.064(0.033) \\
0.070(0.035) \\
0.074(0.033) \\
0.084(0.034) \\
0.097(0.047) \\
0.112(0.068) \\
0.115(0.062) \\
0.114(0.078)\end{array}$ \\
\hline & \multicolumn{2}{|l|}{ Mean $=0.061$} & & \\
\hline
\end{tabular}

Table 2 Density of cephalocaudal samples of peripheral lung tissue in 12 supine subjects with fibrosing alvelolitis

\begin{tabular}{|c|c|c|c|c|}
\hline \multirow{3}{*}{$\begin{array}{l}\text { Height }(\mathrm{cm}) \text { above } \\
(+) \text { or below }(-) \\
\text { mid right atrium }\end{array}$} & \multicolumn{4}{|c|}{$\operatorname{Mean}(S D)$ density $(\mathrm{kg} / \mathrm{l})$} \\
\hline & \multicolumn{2}{|l|}{ Inspiration } & \multicolumn{2}{|l|}{ Expiration } \\
\hline & Right & Left & Right & Left \\
\hline $\begin{array}{l}+4 \\
+3 \\
+2 \\
+1 \\
0 \\
-1 \\
-2 \\
-3 \\
-4 \\
-5 \\
-6 \\
-7 \\
-8 \\
-9\end{array}$ & $\begin{array}{l}0.153(0.110) \\
0.213(0.100) \\
0.224(0.090) \\
0.234(0.083) \\
0.233(0.071) \\
0.227(0.058) \\
0.221(0.052) \\
0.215(0.051) \\
0.218(0.048) \\
0.221(0.044) \\
0.219(0.031) \\
0.225(0.040) \\
0.231(0.042) \\
0.272(0.044) \\
\text { Mean }=0.211\end{array}$ & $\begin{array}{l}0.149(0.042) \\
0.192(0.080) \\
0.181(0.058) \\
0.199(0.065) \\
0.203(0.065) \\
0.193(0.053) \\
0.198(0.053) \\
0.205(0.050) \\
0.200(0.053) \\
0.206(0.045) \\
0.213(0.041) \\
0.215(0.038) \\
0.218(0.051) \\
0.234(0.056)\end{array}$ & $\begin{array}{l}0.275(0.101) \\
0.318(0.080) \\
0.354(0.084) \\
0.392(0.085) \\
0.409(0.077) \\
0.404(0.071) \\
0.414(0.056) \\
0.430(0.055) \\
0.440(0.070) \\
0.510(0.084) \\
0.578(0.102) \\
0.643(0.142) \\
\text { Mean }=0.426\end{array}$ & $\begin{array}{l}0.315(0.082) \\
0.319(0.062) \\
0.361(0.107) \\
0.373(0.106) \\
0.394(0.089) \\
0.400(0.085) \\
0.414(0.056) \\
0.418(0.064) \\
0.445(0.072) \\
0.492(0.114) \\
0.541(0.138) \\
0.597(0.167)\end{array}$ \\
\hline
\end{tabular}

our laboratory in 15 normal subjects, 15 patients with emphysema, and 15 patients with fibrosing alveolitis, the three groups yielding mean values of $0.23,0.74$, and 0.12 $1 / \mathrm{cm} \mathrm{H}_{2} \mathrm{O}$ (Ward et al, unpublished observations). These values compare well with those published elsewhere. ${ }^{18-20}$ Computed tomography confirms that emphysema and fibrosis are not uniformly distributed throughout the lung. Consequently measurements of whole lung compliance substantially underestimate the severity of changes in the damaged parts of the lung. If, for example, the 15 patients with emphysema mentioned earlier had half of their lungs affected the compliance of the emphysematous half would be $1.25 \mathrm{l} / \mathrm{cm} \mathrm{H}_{2} \mathrm{O}$-that is, a fivefold increase. Similarly, if the 15 patients with fibrosing alveolitis had half of their lungs affected the compliance of the fibrotic part would be 0.01 $1 / \mathrm{cm} \mathrm{H}_{2} \mathrm{O}$, a more than 10 fold drop. We believe that it is these severe local changes as well as the effects of gravity on blood vessels that contribute to vertical density gradients in computed tomograms of diseased lungs.

1 Denison DM, Morgan MDL, Millar AB Estimation of regional gas and tissue volumes of the lung in supine man using computed tomography. Thorax 1986;41:620-8.

2 Millar AB, Fromson B, Strickland BA, Denison DM. Computed tomography based estimates of regional gas and tissue volume of the lung in supine subjects wth chronic airflow limitation or fibrosing alveolitis. Thorax 1986;41:932-9.

3 Millar AB, Denison DM. Vertical gradients of lung density in healthy supine men. Thorax 1989;44:485-90.

4 Wilson TA, Bachofen $\mathrm{H}$. A model for mechanical structure of the alveolar duct. J Appl Physiol Respirat Environ Exerc Physiol 1982;52:1064-70.

5 Stamenovic D, Yager G. Elastic properties of air and liquid filled lung parenchyma. J Appl Physiol 1988;65:2562-70.

$6 \mathrm{Kreel} \mathrm{L}$. Computed tomography of the thorax. Radiol Clin North

7 Rosenblum LJ, Mauceri RA, Wallenstein DE, et al. Computed tomography of the lung. Radiology 1978;129:521-4.

8 Goddard PR, Nicholson EM, Laszlo G, Watt I. Computed tomography in pulmonary emphysema. Clin Radiol 1982;33:379-87.

9 Soloman A, Kreel L, McNichol M, Johnson N. Computed tomography in pulmonary sarcoidosis. J Comput Assist Tomogr 1979;3:754-8.

10 Genereux GP. Computed tomography and the lung: review of anatomic and densitometric features with their clinical application. J Can Ass Radiol 1985;36:88-102.

11 Medical Research Council. Definition and classification of chronic bronchitis for clinical epidemiological purposes. Lancet 1965;ii:755.

12 Murray J. The normal lung. Philadelphia: Saunders, 1976:86-8.

13 Weibel ER. The pathway for oxygen. Cambridge, Massachusetts: Harvard University Press, 1984:281, 289.

14 Coddington R, Mera SL, Goddard PR, Bradfield JWB. Pathological evaluation of computed tomographic images of lungs. J Clin Pathol 1982;35:536-40.

15 Bergin C, Muller N, Nichols DM, et al. The diagnosis of emphysema; a computed tomographic-pathologic correlation. Am Rev Respir Dis 1986;133:541-6.

16 Ren H, Hruban RH, Kuhkman JE, et al. Computed tomography of inflation fixed lungs: the beaded septum tomography of inflation fixed lungs: the beaded septum sign of pulmonar

17 Meziane MA, Khouri NF, Hruban RH, et al. High resolution CT of the lung parenchyma with pathologic correlaion. RadioGraphics 1988;1:27-54.

18 Gibson GJ, Pride NB. Pulmonary mechanics in fibrosing alveolitis. Am Rev Respir Dis 1977;116:637-47.

19 Fulmer JD, Roberts WC, Von Gal ER, Crystal RG. Small airways $\mathrm{n}$ ideopathic pulmonary fibrosis. J Clin Invest 1977;60:595-610.

20 Colebatch HJH, Finucane KE, Smith MM. Pulmonary conductance and elastic recoil relationships in asthma and emphysema. J Appl Physiol 1973;34:143-53. 